\title{
Outcome of Post Esophageal Variceal Band Ligation with Sucralfate and Proton Pump Inhibitor vs. Proton Pump Inhibitor Alone in Cirrhotic Patients
}

Binod Karki ${ }^{l}$, Ramila Shresthal, Bidhan Nidhi Poudel ${ }^{l}$, Sudhamshu KC ${ }^{2}$, Dibas Khadkal, Suresh Thapa ${ }^{l}$, Bibek Kumar Purbey ${ }^{l}$, Sanjit Karki ${ }^{1}$, Pukar Thapa', Amrendra Mandal ${ }^{3}$

${ }^{1}$ Gastroenterology Unit, Bir Hospital, National Academy of Medical Sciences, Kathmandu, Nepal ${ }^{2}$ Liver Unit, Bir Hospital, National Academy of Medical Sciences, Kathmandu, Nepal

${ }^{3}$ Internal Medicine, Interfaith Medical Center, Brooklyn, New York, USA

\section{ABSTRACT}

Introduction: Endoscopic band ligation is the mainstay of treatment in bleeding varices in cirrhosis. Subsequent bleeding from the band ulcers is a possible complication. Proton pump inhibitors and Sucralfate are commonly used post band ligation and often in combination. The aim of the study was to identify the advantage of combining Sucralfate to proton pump inhibitor in reducing the number and size of band ulcers.

Materials and Methods: This was an open label comparative study conducted in a tertiary level hospital of Nepal. Patients with cirrhosis after band ligation were included. Eligible patients were randomized into a proton pump inhibitor alone (Group A) or proton pump inhibitor and sucralfate group (Group B) and they underwent upper gastrointestinal endoscopy after two weeks. Baseline parameters, number and mean size of band ulcers were compared.

Results: A total of 58 patients, 29 in each group, were evaluated. The baseline characteristics were comparable. EBL was done for bleeding varices in $51.7 \%$ and as primary prophylaxis in the rest of them. All the patients had band ulcers after two weeks. The mean size of the largest ulcer was $1.62 \pm 0.72$ and $1.10 \pm 0.60(p=0.78)$ respectively in group A and B. Low albumin was significantly associated with OR of 8.7 (95\% CI:1.68-44.99) for the formation of multiple (more than two) ulcers $(\mathrm{p}=0.01)$.

Conclusions: The ulcer formation was universal after band application. The addition of sucralfate did not offer more benefits in terms of the number and mean size of the ulcer. Low albumin was the independent predictor for multiple ulcer formation.

Keywords: Band ligation; Band Ulcer; Esophageal varices; Proton pump inhibitors; Sucralfate
Correspondence:

Dr. Binod Karki,

DM Resident

Gastroenterology Unit, Bir Hospital,

National Academy of Medical Sciences, Kathmandu,

Nepal

ORCID ID: 0000-0002-4650-95

Email: binodkarki@yahoo.com

Submitted : $21^{\text {st }}$ July 2019

Accepted : $15^{\text {th }}$ November 2019

Source of Support: None

Conflict of Interest: None

Citation: Karki B, Shrestha R, Poudel BN, KC Sudhamshu, Khadka Dibas, Thapa S, et al. Outcome of post esophageal variceal band ligation with sucralfate and proton pump inhibitor vs. Proton pump inhibitor alone in cirrhotic patients. NMJ 2019;2 (2): 209-14. DOI: $10.3126 /$ nmj.v2i2.24930 


\section{INTRODUCTION}

Portal hypertension is the pathophysiologic basis for the formation of oesophageal varices in cirrhosis. ${ }^{1}$ Bleeding from varices occurs in about $30 \%$ of patients with varices and carries a mortality risk of $15 \%-30 \%$ per episode. ${ }^{2}$ Endoscopic sclerotherapy (ES) was the standard of care until the introduction of more effective endoscopic band ligation (EBL) technique in $1986 .{ }^{3,4}$ Post-EBL bleeding was reported up to $7.7 \%$ in one study. ${ }^{5}$ Once there is EBL ulcer bleeding, the management can be challenging and the mortality can reach as high as $52 \%{ }^{6}$

The EBL ulcers heal faster than post-sclerotherapy ulcers. ${ }^{7}$ Use of either proton pump inhibitors (PPI) or mucoprotectant like Sucralfate can reduce the ulcer size and its numbers. ${ }^{8} \mathrm{~A}$ combination of PPI and sucralfate are often used post banding although the evidence for the benefit of such combination is still not clear. The aim of this study was to find out if the addition of sucralfate to PPI would lead to faster healing of the EBL ulcers in terms of its number and size leading to fewer ulcer related complications.

\section{MATERIALS AND METHODS}

This was a hospital based open label randomized study conducted in one of the tertiary referral hospitals of Nepal. The study was conducted in the Gastroenterology and Hepatology Unit of Bir Hospital from May to December 2018. Ethical approval was taken from the institutional review board of the institute. The trial was registered in the UMIN database as UMIN-000035296 (https://www.umin.ac.jp/ctr/). Data collection was started after the Institute Review Board (IRB) approval. Patients more than 18 years and less than 65 years, who underwent EBL either as primary or secondary prophylaxis were included in the study after informed consent. Patients presenting with fundal varices, having endoscopically confirmed pre-existing oesophageal ulcers and with co-morbidities like diabetes, bleeding disorders, heart failure, chronic kidney disease and malignancy were excluded. Clinical, epidemiological, laboratory and endoscopic data were collected at the time of randomization and during follow up.

Eligible patients were randomized into a PPI alone group (Group A) or PPI plus sucralfate group (Group B). A sealed envelope method was used for randomization. All of them underwent a variceal band ligation procedure using a multi-band ligator device with six set rubber bands attached to the distal end of the gastroscope. The number of bands applied depending upon the number and size of varices with a maximum number of bands applied in a session to be six. The patient was observed for any post procedural chest pain that was assessed subjectively and graded as no, mild, moderate and severe described by the patient as follows-Mild: chest pain that could be tolerated, Moderate: could be tolerated in between and Severe: awaken the patient from sleep and need medication.

Patients in group A were given Tab pantoprazole $40 \mathrm{mg}$ twice daily for 14 days where as patients in group B were prescribed syrup Sucralfate $10 \mathrm{ml}$ four times daily in addition to pantoprazole for the same duration. All patients were inquired by telephone at the end of one week regarding post banding bleeding (haematemesis and/or melena), chest pain (mild, moderate and severe) and dysphasia. At the end of two weeks, all the patients were assessed clinically. Upper gastrointestinal endoscopy was done to assess the presence of EBL ulcers, number of ulcers and the size of ulcers. The size of the largest ulcer was measured using the measurement of opened standard biopsy forceps which was taken as $5 \mathrm{~mm}$.

The primary outcome was to compare the incidence of EBL ulcers, their number and mean size of the largest ulcer in both the groups. The secondary outcome was to find the incidence of post EBL chest pain, bleeding or death due to any cause within two weeks of the procedure. We also aimed to find out if there were any predictors of multiple ulcers $(>2)$.

The sample size was calculated using the incidence of EBL ulcer in the study done by Mohamed Amin Sakr et $\mathrm{al}^{9}$ who used sucralfate to reduce the incidence of post EVL ulcers, where 12 patients $(38.7 \%)$ in the study group developed post-band ulcers versus 23 patients $(74.2 \%)$ in the control group. It was calculated that a total 58 patients (29 in each arm) would be required for the analysis with an alpha error at 0.05 and the power of study at $80 \%$. The participants were randomized using sealed envelops containing either group A or group B inside. Both treating physicians and the patients knew about the treatment being offered to them.

We used intention-to-treat analysis for all efficacy analyses, analyzing all participants who underwent randomization. Continuous variables were expressed as mean \pm standard deviation (SD) and categorical variables as numbers and frequencies. Categorical variables were compared using the $\chi^{2}$ test and continuous variables with independent $t$ test. Bi variate and multivariate analysis were carried out to assess the degree of association between the formation of multiple ulcers $(>2)$ and the above-mentioned variables. All statistical analyses were performed using the SPSS 20.0 statistical package.

\section{RESULTS}

A total of 58 patients were included in the study with 29 in each group (fig. 1).

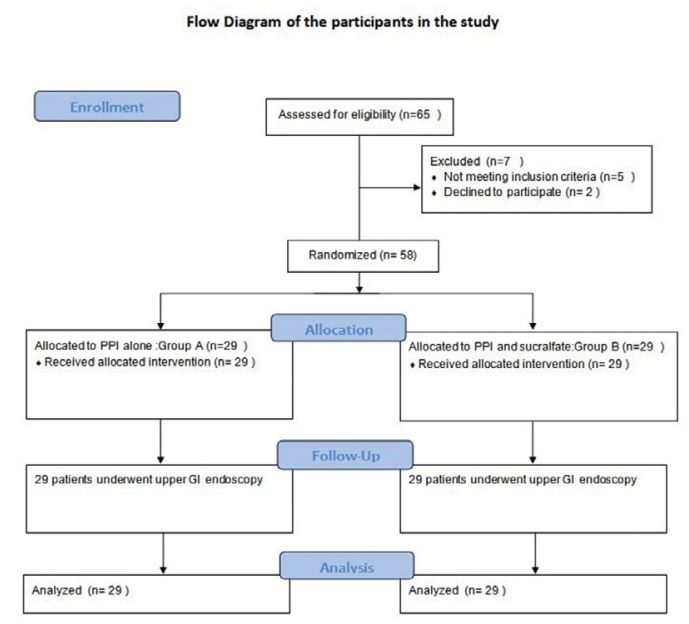

Figure 1: Participant flow chart as per CONSORT guideline 
The study period was of eight months commencing from May 2018 and ended in December 2018 after the fulfillment of sample size. The baseline demographic and lab parameters were comparable in both the arms (Table 1).

Table 1: Baseline characteristics in the study groups $(n=58)$

\begin{tabular}{|c|c|c|c|}
\hline Variables (Mean \pm SD) & Group A (PPI alone) $\mathbf{n}=29$ & Group B (PPI + Sucralfate) $n=29$ & p-value \\
\hline Age & $45.48( \pm 6.78)$ & $44.93( \pm 8.4)$ & 0.56 \\
\hline Sex ( male ) & $25(86.21 \%)$ & $26(89.7 \%)$ & 1.0 \\
\hline Bleeder & $16(55.2 \%)$ & $12(41.4 \%)$ & 0.29 \\
\hline Etiology - Alcohol & $27(93.1 \%)$ & $27(93.1 \%)$ & 1.0 \\
\hline \multicolumn{4}{|l|}{ Child Pugh } \\
\hline $\mathbf{A}$ & 0 & $2(6.9 \%)$ & \multirow{3}{*}{0.34} \\
\hline B & $16(55.2 \%)$ & $17(58.6 \%)$ & \\
\hline $\mathbf{C}$ & $13(44.8 \%)$ & $10(34.5 \%)$ & \\
\hline Albumin & $2.84 \pm 0.41$ & $2.97 \pm 0.65$ & 0.37 \\
\hline Bilirubin & $4.9 \pm 3.2$ & $4.3 \pm 3.2$ & 0.78 \\
\hline INR & $1.64 \pm 0.45$ & $1.59 \pm 0.22$ & 0.62 \\
\hline Hb & $9.3 \pm 1.7$ & $10.05 \pm 0.89$ & 0.06 \\
\hline Creatinine & $1.15 \pm 0.72$ & $1.1 \pm 0.6$ & 0.78 \\
\hline CTP score & $9.5 \pm 1.8$ & $8.9 \pm 1.5$ & 0.16 \\
\hline APRI, Median(IQR) & $2.3(1.70,3.75)$ & $2.3(1.20,3.30)$ & $0.56^{*}$ \\
\hline MELD & $18.24 \pm 4.6$ & $17.24 \pm 3.67$ & 0.36 \\
\hline \multicolumn{4}{|c|}{ Upper GI endoscopy findings } \\
\hline No of varices & $3.93 \pm 0.25$ & $3.97 \pm 0.18$ & 0.56 \\
\hline No of Bands applied & $5.52 \pm 0.7$ & $5.62 \pm 0.6$ & 0.56 \\
\hline
\end{tabular}

*Mann-whitney test

The mean age of the patients was $45.48 \pm 6.78$ years and $44.93 \pm 8.4$ years in the study groups A and B. There was male predominance with $87.9 \%$ out of total. Almost half of the patients received the esophageal band ligation for the secondary prophylaxis i.e. as a part of the treatment for the bleeding. The alcohol was the most common etiology of chronic liver disease in $93.1 \%$ followed by Hepatitis B and Non-alcoholic Steatohepatitis. Most of the patients were in either Child B or Child C class. The mean albumin was $2.84 \pm 0.41 \mathrm{mg} / \mathrm{dl}$ and $2.97 \pm 0.65 \mathrm{mg} / \mathrm{dl}(\mathrm{p}=0.37)$ in the study groups A and B respectively. The bilirubin, protrhombin time with international normalized ration (INR), Aspartate aminotransferase to platelet ratio index (APRI) and model for end-stage liver disease (MELD) scores were comparable.

On upper gastrointestinal endoscopy, all the patients have large varices with red color signs. Most of them had more than three varices and the mean number of bands applied were $5.52 \pm$ 0.7 and $5.62 \pm 0.6$ in group A and B respectively (Table 1). All the patients were called for follow up at the end of two weeks. The patients in both groups have similar incidences of chest discomfort and bleeding complication. One patient in each group had post band ulcer related bleeding and both were managed conservatively with hospital admission, intravenous octreotride, and blood products. There was no mortality for two weeks in any of the groups.

All patients had at least one band ulcer (fig. 2) at the end of two weeks. There were $2.79 \pm 0.97$ and $2.76 \pm 0.63$ number of ulcers in groups $\mathrm{A}$ and $\mathrm{B}$ respectively. The mean size of the largest ulcer was $1.62 \pm 0.72 \mathrm{~cm}$ and $1.10 \pm 0.6 \mathrm{~cm}(\mathrm{p}=0.78)$ in groups $A$ and $\mathrm{B}$ respectively and the difference was not statistically significant (Table 2). The group A had more than three ulcers compared to group B $(20.71 \%$ vs $10.5 \%)$ but it did not reach statistical significance, $\mathrm{p}=0.34$ (fig. 3).

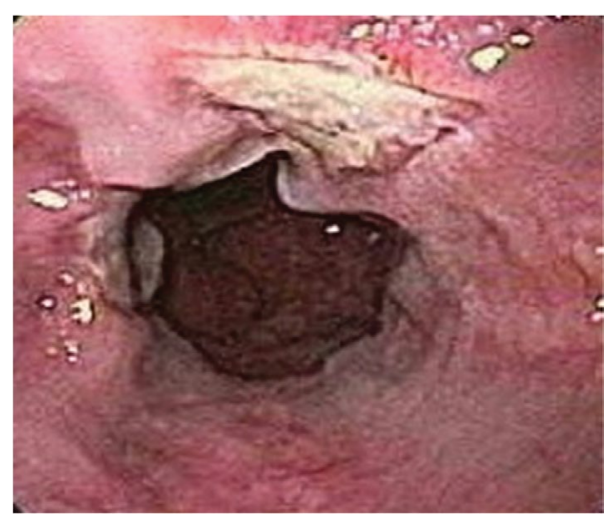

Figure 2: Representative band ulcer in the study

\section{Comparison of No of ulcer in two groups}

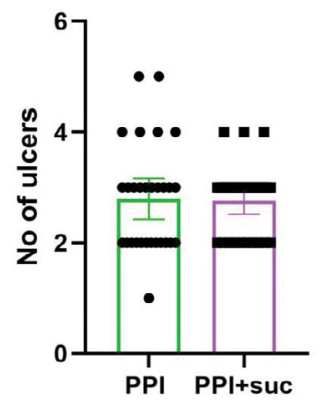

Treatment groups

Figure 3: Comparison of number of ulcers in both the groups 
Table 2 : Upper GI endoscopic findings on follow up at the end of two weeks

\begin{tabular}{|c|c|c|c|c|}
\hline $\begin{array}{c}\text { Variables } \\
(\text { Mean } \pm \text { SD })\end{array}$ & & $\begin{array}{c}\text { Group A, } \\
\mathbf{n}=\mathbf{2 9}\end{array}$ & $\begin{array}{c}\text { Group B, } \\
\mathbf{n}=\mathbf{2 9}\end{array}$ & $p$ value \\
\hline \multirow{5}{*}{ Ulcer } & 1 & $1(3.4 \%)$ & 0 & \multirow{5}{*}{0.34} \\
\hline & 2 & $12(41.4 \%)$ & $10(34.5 \%)$ & \\
\hline & 3 & $10(34.5 \%)$ & $16(55.2 \%)$ & \\
\hline & 4 & & & \\
\hline & 5 & & & \\
\hline Size (largest ulcer) & & $1.62( \pm 0.72)$ & $1.10( \pm 0.6)$ & 0.78 \\
\hline Chest pain & & $6(20.7 \%)$ & $7(24.1 \%)$ & 0.75 \\
\hline EBL ulcer bleeding & & $1(3.4 \%)$ & $1(3.4 \%)$ & 1.0 \\
\hline
\end{tabular}

Table 3: Bi-variate and multivariate analysis for the formation of multiple $(>2)$ ulcers

\begin{tabular}{lllll}
\hline Variables & $\begin{array}{l}\text { Crude Odds } \\
\text { ratio (OR) }\end{array}$ & p value & $\begin{array}{l}\text { Adjusted OR } \\
\text { With 95\% CI }\end{array}$ & p value \\
\hline $\begin{array}{l}\text { Group (Su- } \\
\text { cralfate) }\end{array}$ & $1.54(0.54-4.45)$ & 0.42 & - & - \\
\hline $\begin{array}{l}\text { Platelet }<\mathbf{1 5 0} \\
\text { lac/cc }\end{array}$ & $1.26(0.30-5.30)$ & 0.75 & - & - \\
\hline APRI > 2.2 & $1.73(0.59-5.01)$ & 0.30 & - & - \\
\hline INR $>\mathbf{1 . 7}$ & $1.06(0.26-4.26)$ & 0.94 & - & - \\
\hline MELD >10 & $1.68(1.35-208)$ & 1.00 & - & - \\
\hline $\begin{array}{l}\text { Albumin }< \\
\mathbf{2 . 8} \text { mg/dl }\end{array}$ & $\begin{array}{l}11.12(2.26- \\
54.77)\end{array}$ & 0.001 & $8.7(1.68-44.99)$ & 0.01 \\
\hline CTP score $>$ 9 & $3.68(1.18-$ & 0.020 & $2.1(0.60-7.23)$ & 0.24 \\
& $11.47)$ & & & \\
\hline
\end{tabular}

Low albumin $<2.8 \mathrm{mg} / \mathrm{dl}$ and CTP score $>9$ were significantly associated with the formation of multiple ulcers on bi-variate analysis however only low albumin reached statistical significance with OR of 8.7 ( 95\% CI:1.68-44.99) (Table 3). The regression model was fit ( $\mathrm{p}$ value for Hosmer Lemeshow test $=0.75$ ) with a significant Omnibus test value of $p=0.001$. When the ROC curve was analyzed for the serum albumin and the formation of multiple ulcers, the AUROC was 0.83 with a statistically significant $\mathrm{p}$ value $<0.001,95 \%$ CI:0.72-0.95( fig. 4).

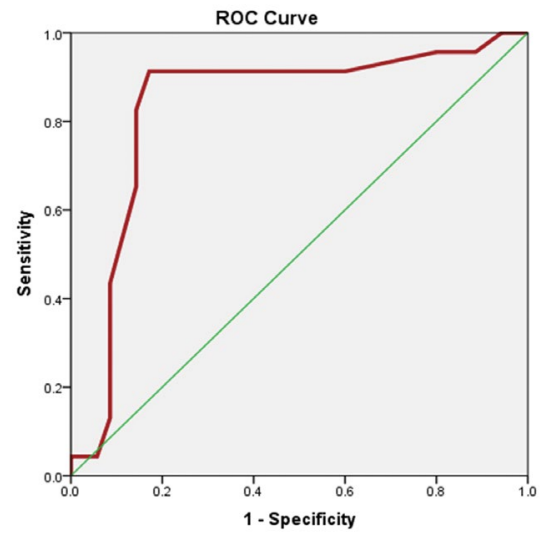

Figure 4: Receiver-operator characteristics (ROC) curve for serum albumin to predict the formation of multiple band ulcers.

The best cut off value of albumin from the ROC co-ordinates of the curve was $2.85 \mathrm{mg} / \mathrm{dl}$ with a sensitivity of $91.3 \%$ and specificity of $83.0 \%$ for the prediction of multiple ulcers.

\section{DISCUSSION}

The most common etiology of chronic liver disease in our study was alcohol $(93.1 \%)$. It was different from the Korean study ${ }^{10}$ where alcohol was etiology in only $38.6 \%$ and $51.1 \%$ had hepatitis $\mathrm{B}$ infection. In another study by Sakr et $\mathrm{al}^{9}$ from Egypt, hepatitis $\mathrm{C}$ was the major cause in $96.8 \%$ followed by schistosomiasis but not alcohol. The alcohol predominance in our study can be explained due to the higher number of male patients in our study. The male population are likely to consume more alcohol in our culture. In a study done previously in our institute, alcohol was the main etiology for chronic liver disease. ${ }^{11}$

EBL has become the mainstay of the management of esophageal varices in chronic liver disease. ${ }^{12}$ The use of PPI has been shown to decrease the EBL related bleeding in a retrospective study by Kang SH et $\mathrm{al}^{10}$ where 14 out of 505 patients developed post EBL bleeding and in the multivariate analysis not administrating PPIs (OR 8.2,p=0.002) was associated with bleeding. The role of sucralfate in ulcer healing was done mainly for the sclerotherapy related ulcers and has shown to be effective. ${ }^{13}$ This is the first of its kind of study where we have tried to combine PPI and sucralfate for the treatment of band ulcers.

In our study, all the patients had at least one ulcer at the end of two weeks. It is consistent with the finding that ulcer formation is not the complication but the part of the natural history in the esophageal band ligation. ${ }^{14}$ The ulcer formation is the universal process that eventually heals by fibrosis and thus helps in the obliteration of the varices. A study by Sakr et $\mathrm{al}^{9}$ where the patients were subjected to endoscopy at two weeks, only $56.4 \%$ had ulcers unlike our results. Whether the predominant etiology that was alcohol in our study has resulted in delayed ulcer healing or there are other factors contributing to slow healing of ulcers needs to be analyzed further.

There were no statistically significant differences in the number and the size of the ulcer in both the study groups. The PPI alone group had more than three ulcers compared to the other group. The number and size of the ulcer have been taken as the surrogate marker for the risk of bleeding in our study since the sample size would have been very high if we had taken the incidence of post EBL bleeding. There are however no prospective studies to confirm that the increased number and larger ulcers will translate clinically into more incidences of bleeding complications.

The use of PPI had shown to be effective in reducing the size of ulcer in a randomized trial where the mean size of ulcer was $37 \mathrm{~mm}^{2}$ and $82 \mathrm{~mm}^{2}$ in the group with pantoprazole $40 \mathrm{mg}$ vs placebo $(\mathrm{p}<0.01) .{ }^{15}$ Similarly the use of sucralfate has also been shown to decrease the incidence as well as the mean size of post band ulcers; incidence : $38.7 \%$ in sucralfate group vs $74.2 \%$ in the control group $(\mathrm{p}=0.005)$ and mean size: $2.7 \mathrm{~mm} \pm 1.2$ vs $3.8 \mathrm{~mm} \pm 1.7(\mathrm{p}=0.043)$ respectively. ${ }^{9}$ This finding was not reproduced in our study when we used the combination of both pantoprazole and sucralfate. The utility of using sucralfate have been questioned in other trial previously by Nijhawan et al ${ }^{16}$ where the authors showed that all the post band ulcers heal by third week irrespective of use of sucralfate. In a study by Wu CK et $a l,{ }^{17}$ where the authors retrospectively evaluated 637 patients who underwent EBL with either acid suppression therapy or none, they found that adjuvant acid suppression may not change the re-bleeding rate and mortality outcome. 
Since the formation of band ulcer in our study was universal unlike the previous study, ${ }^{9}$ we tried to find out if there are any variables associated with this occurrence by using the bi-variate and multivariate analysis. Low albumin was significantly associated with the occurrence of multiple ulcers. We took cut off of albumin as less than 2.8 as it represented the lowest threshold while calculating CTP score. The finding was similar to the study by Vanbiervliet $\mathrm{G}$ et $\mathrm{al}^{6}$ where albumin was shown to be predictor of bleeding risk along with presence of peptic esophagitis, high APRI and low prothrombin index. The low albumin can be associated with delayed ulcer healing and thus more ulcer related complications. Low albumin can also explain the universal occurrence of ulcers in our study. It also been associated with significant recurrent bleeding and mortality in peptic ulcer disease. ${ }^{18}$

There are some limitations in our study. We could not take the incidence of ulcer bleeding as the primary outcome due to limited sample size. This was single center study and was not

\section{REFERENCES}

1. Hughes RA, Rees JH. Clinical and epidemiologic features of Guillain-Barré syndrome. J Infect Dis. 1997; 176:S92-S98. Crossref

2. Jiang G-X, de Pedro-Cuesta J, Fredrikson S. Guillain-Barré syndrome in South-West Stockholm, 1973-1991, 1. Quality of registered hospital diagnoses and incidence. Acta Neurol Scand. 1995;91(2):109-17. Crossref

3. Witsch J, Galldiks N, Bender A, Kollmar R, Bösel J, Hobohm C, et al. Long-term outcome in patients with Guillain-Barré syndrome requiring mechanical ventilation. J Neurol. 2013;260(5):1367-74. Crossref

4. Kalita J, Ranjan A, Misra UK. Outcome of guillain-barre syndrome patients with respiratory paralysis. Qjm. 2016;109(5):319-23. Crossref

5. Nithyashree N, Dhanaraj M, Kumar S, Saraswathi M. Factors predicting poor outcome in patients with fulminant Guillaine-Barré syndrome. Ann Indian Acad Neurol [Internet]. 2014;17(4):463. Crossref

6. Nagappa M, Rahul W, Sinha S, Bindu PS, Mathuranath PS, Rao $\mathrm{S}$, et al. Guillain Barre Syndrome in the elderly: Experience from a tertiary-care hospital in India. J Clin Neurosci. 2017;46:45-9. $\underline{\text { Crossref }}$

7. van Doorn PA, Ruts L, Jacobs BC. Clinical features, pathogenesis, and treatment of Guillain-Barré syndrome. The Lancet Neurology. 2008;7:939-50. Crossref

8. Hughes RAC, Swan AV, van Doorn PA. Corticosteroids for Guillain-Barré syndrome. Cochrane Database of Systematic Reviews 2010, Issue 2. Art. No.: CD001446. Crossref

9. Guillain-Barré Syndrome Steroid Trial Group. Double-blind trial of intravenous methylprednisolone in Guillain-Barré syndrome. Lancet. 1993;341(8845):586-90. Crossref

10. Hughes RAC. Randomised trial of plasma exchange, intravenous immunoglobulin, and combined treatments in Guillain-Barre syndrome. Lancet. 1997;349(9047):225-30. Crossref

11. Jayalakshmi S, Vooturi S. Legal challenges in neurological practice. Ann Indian Acad Neurol [Internet]. 2016;19(5):S3-8. Available from: $\underline{\text { Crossref }}$ blinded. The compliance for the use of sucralfate was inquired at the follow up and found to be good, however it is likely that the participants might have missed or did not take the medications as advised.

\section{CONCLUSIONS}

Adding sucralfate in a patient who is already taking PPI may not offer added benefit to reduce the number and size of ulcers. It will only add to the cost of the treatment. Low albumin is the independent predictor of multiple ulcers formation after esophageal band ligation.

\section{ACKNOWLEDGEMENTS}

We acknowledge Dr Kharendra Chaudhary who has helped during data acquisition and all the staffs of our department.

12. Islam B, Islam Z, Rahman S, Endtz HP, Vos MC, Van Der Jagt M, et al. Small volume plasma exchange for Guillain-Barré syndrome in resource-limited settings: A phase II safety and feasibility study. BMJ Open 2018;8:e022862. $\underline{\text { Crossref }}$

13. Batra A, Periyavan S. Role of low plasma volume treatment on clinical efficacy of plasmapheresis in neuromyelitis optica. Asian $\mathrm{J}$ Transfus Sci [Internet]. 2017;11(2):102. $\underline{\text { Crossref }}$

14. Fokke C, Berg van den B, Drenthen J, Walgaard C, Doorn van PA, Jacobs BC. Diagnosis of Guillain-Barré syndrome and validation of Brighton criteria, Brain 2014;137:33-43. Crossref

15. Narayanan R, James N, Ramachandran K, Jaramillo MJ. GuillainBarré Syndrome presenting with bilateral facial nerve paralysis: a case report. Cases J [Internet]. 2008;1(1):379. Crossref

16. Sekiguchi Y, Misawa S, Suichi T, Amiono H, Shibuya K, Kuwabara S. Facial nerve palsy and disease severity in Guillain-Barre syndrome. J Neurol Sci [Internet]. 2017;381:1073. Crossref

17. Verma R, Chaudhari TS, Raut TP, Garg RK. Clinicoelectrophysiological profile and predictors of functional outcome in Guillain-Barre syndrome (GBS). J Neurol Sci. 2013;335:105-11. $\underline{\text { Crossref }}$

18. Hafsteinsdóttir B, Ólafsson E, Jakobsson F. Incidence and outcome of Guillain-Barré syndrome in Iceland: A population-based study. Acta Neurol Scand. 2018;138(5):454-8. Crossref

19. Devos D, Magot A, Perrier-Boeswillwald J, Fayet G, LeclairVisonneau L, Ollivier Y, et al. Guillain-Barré syndrome during childhood: Particular clinical and electrophysiological features. Muscle and Nerve. 2013;48(2):247-51. Crossref

20. Feasby TE, Gilbert JJ, Brown WF, Bolton CF, Hahn AF, Koopman $\mathrm{WF}$, et al. An acute axonal form of guillain-barrée polyneuropathy. Brain. 1986;109(6):1115-26. Crossref

21. Ho TW, Mishu B, Li CY, Gao CY, Cornblath DR, Griffin JW, et al. Guillain-barré syndrome in Northern China relationship to Campylobacter jejuni infection and anti-glycolipid antibodies. Brain. 1995;118(3):597-605. Crossref

22. Irani DN, Cornblath DR, Chaudhry V, Borel C, Hanley DF. Relapse in Guillain-Barre syndrome after treatment with human immune globulin. Neurology 1993;43(5):872-5. $\underline{\text { Crossref }}$ 
23. Romano JG, Rotta FT, Potter P, Rosenfeld V, Santibanez R, Rocha $\mathrm{B}$, et al. Relapses in the Guillain-Barre syndrome after treatment with intravenous immune globulin or plasma exchange. Muscle and Nerve. 1998;21(10):1327-30. $\underline{\text { Crossref }}$

24. Castro LH, Ropper AH. Human immune globulin infusion in Guillain-Barré syndrome: worsening during and after treatment. Neurology. 1993;43(5):1034-6. Crossref

25. Van Den Berg B, Bunschoten C, Van Doorn PA, Jacobs BC. Mortality in Guillain-Barré syndrome. Neurology. 2013;80(18):1650-4. Crossref

26. Lünemann JD, Quast I, Dalakas MC. Efficacy of Intravenous Immunoglobulin in Neurological Diseases. Vol. 13, Neurotherapeutics. 2016. p. 34-46. Crossref

27. Dalakas MC, Clark WM. Strokes, thromboembolic events, and IVIg: Rare incidents blemish an excellent safety record. Neurology. 2003;60(11):1736-7. Crossref 